\title{
Determining the Generalized Discount Rate for Risky Projects
}

\author{
Lanlan Luo $^{1} \cdot$ Shou Chen ${ }^{1} \cdot$ Ziran Zou $^{1}$
}

Accepted: 9 July 2020 / Published online: 18 July 2020

(C) The Author(s) 2020

\begin{abstract}
It is widely recognized that the evaluation of risky projects critically depends on how the riskiness of future benefits is treated. Standard discounting theories are based on the assumption that risks that are uncorrelated with aggregate risk are diversified, so that projects' idiosyncratic risk is not priced. However, this may not be true for long-term risky projects, such as those with persistent idiosyncratic shocks. In this study, we investigate the impact of both aggregate risk and nondiversifiable idiosyncratic risk on the discount rate for risky projects. We extend the generalized discount rate to the case of persistent shocks. A particular advantage of the generalized discount rate is that it can be applied in the setting of incomplete markets. We show that nondiversifiable idiosyncratic risk reduces the discount rate, and increases the present value of projects' future uncertain benefits. We further apply our findings to the evaluation of emissions reduction projects.
\end{abstract}

Keywords Generalized discount rate $\cdot$ Term structure $\cdot$ Idiosyncratic risk $\cdot$ Cost-benefit analysis $\cdot$ Emissions reduction projects

JEL Classification $\mathrm{H} 43 \cdot \mathrm{D} 61 \cdot \mathrm{G} 12$

\section{Introduction}

The choice of an appropriate discount rate is a critical and contentious issue in environmental and resource economics, as it determines whether a project passes the cost-benefit test. This is especially true for projects with long time horizons and uncertain benefits (Arrow et al. 2013, 2014). The discount rate for risky projects is critically dependent upon the riskiness of future benefits. Classical discounting models implicitly assume that a project's idiosyncratic risk can be diversified, and therefore, this risk is not priced (Gollier 2014, 2016b; Dietz et al. 2018). However, public projects are not arbitrarily divisible (Traeger 2013), and idiosyncratic risk should be incorporated into the discount rate of climate change investments (Weitzman 2013). In this study, we investigate the impact of

Shou Chen

chenshou@hnu.edu.cn

Ziran Zou

zouziran@hnu.edu.cn

1 Business School of Hunan University, Changsha 410082, Hunan, China 
both aggregate risk and nondiversifiable idiosyncratic risk on the discount rate for risky projects.

In our model, we assume that risky projects' benefits are affected by both uncertainties of consumption growth and project productivity. Traeger (2013) initially defines a generalized discount rate (GDR) that is determined by the joint distribution of an uncertain consumption growth rate and project productivity rate. The GDR, as a devaluation rate, measures the present value consumption loss due to a future shift to productive consumption. Motivated by Traeger (2013), we use the GDR framework to evaluate risky projects. We relax the assumption of perfect serial correlation in Traeger $(2013)^{1}$ and assume that both consumption growth and project productivity rates are time-varying.

Based on Bansal and Yaron (2004), we assume that both the consumption growth rate and project productivity rate contain small but persistent predictable components. The logic behind this assumption is that the consumption growth rate in the current stage is affected by that of the previous stages. Meanwhile, the project productivity rate is affected by both the consumption growth rate of the previous stages as well as idiosyncratic persistent components of the previous stages, which are independent of the consumption growth process.

We find that two effects determine the term structure of the GDR. The first is the relative wealth effect, which captures the difference between the future wealth level in the economy and that of the project. The second is the joint risk effect, which reflects the impact of the overall uncertainty of consumption growth and project productivity. If the consumption growth and project productivity rates have no serial correlation, the GDR is flat. Otherwise, the joint risk effect reduces the GDR, while the impact of the relative wealth effect on GDR depends on the relative level of social wealth growth and project productivity. When the small consumption growth rates dominate the valuation of marginal consumption and, simultaneously, the large productivity rates dominate the payoff expectations, the relative wealth effect reduces the GDR. The combined effect thus leads to a decreasing GDR term structure. However, if a high social wealth growth is accompanied by a low project productivity, the relative wealth effect increases the GDR. Furthermore, if the increasing trend due to the relative wealth effect overwhelms the decreasing trend due to the joint risk effect, the combined effect makes the GDR increase over time for small maturities.

We further apply our findings to the evaluation of emissions reduction projects whose nondiversifiable idiosyncratic risk stems from persistent shocks due to climate sensitivity changes. Our numerical application implies that the discount rate for risky projects is overestimated and the present value (PV) of emissions reduction benefits is underestimated when ignoring the impact of the nondiversifiable idiosyncratic risk. Furthermore, our numerical application also illustrates that the higher the intensity of macroeconomic impact, the smaller the GDR and the greater the PV of emissions reduction benefits.

Our study contributes to the discounting theory for risky projects in three ways. First, we provide a general approach to evaluate long-term risky projects by extending the GDR. A particular advantage of this approach is that it can be applied to evaluate risky projects in the setting of incomplete markets. Second, we explicitly quantify the impact of idiosyncratic risk on the discount rate for risky projects. We demonstrate that nondiversifiable idiosyncratic risk reduces the discount rate and increases the PV of projects' future uncertain benefits. If the idiosyncratic risk is diversifiable, our result is consistent with that

\footnotetext{
1 Traeger (2013) states that such simplified models of perfect serial correlation should not be used to derive quantitative policy guidance.
} 
of the classical discounting model. Third, we apply our findings to the evaluation of emissions reduction projects. Our extended GDR approach can avoid underestimating the PV of an emissions reduction project when it is significantly affected by persistent idiosyncratic shocks associated with climate sensitivity.

Our study is closely related to the risk-adjusted discount rate (RADR) literature on evaluating risky projects (Gollier 2014, 2016b; Dietz et al. 2018). The RADR literature is based on the consumption-based capital asset pricing model (CCAPM) of Lucas (1978) in the setting of complete markets. The corresponding RADR is the sum of a risk-free discount rate and a project-specific risk premium. The project-specific risk premium is determined by the CCAPM beta of the project and the macro risk premium, and there is no risk premium associated to idiosyncratic risk. However, future markets for long-term projects do not always exist or are incomplete (Traeger 2013), and therefore the idiosyncratic risk may not be diversified. Furthermore, Weitzman (2013) states that the idiosyncratic risk of a long-term risky project with environmental impacts should be priced. Motivated by Traeger (2013) and Weitzman (2013), by extending the GDR, we explicitly quantify the impact of a project's idiosyncratic risk on the discount rate. Our research enriches the discounting theory of risky projects in the setting of incomplete markets. This paper is also linked to literature on the discount rate for projects with certain future benefits. There are two streams to investigate risk-free discount rates (Groom et al. 2005; Arrow et al. 2013, 2014; Cropper et al. 2014): the consumption-based approach ${ }^{2}$ and the expected net present value approach. ${ }^{3}$ We lean on the consumption-based approach to define the relative wealth effect. Inspired by the expected net present value approach, we incorporate the persistent shocks of productivity rate into our model. This paper is also linked to recent literature on the ecological discount rate, which is used to evaluate natural capital such as environmental goods and services (Hoel and Sterner 2007; Gollier 2010, 2019). The GDR is consistent with the ecological discount rate if the degree of the substitutability of natural capital can be used to measure the productivity of environmental services.

The remainder of this paper is organized as follows. In Sect. 2, we present the extended GDR and introduce two effects that determine the term structure of the GDR. In Sect. 3, we discuss the term structure of the GDR and analyse the impact of the nondiversifiable idiosyncratic risk. In Sect. 4, we present a numerical application. We conclude with Sect. 5.

\section{Obtaining the Generalized Discount Rate}

Here, we extend the GDR with time-varying consumption growth and project productivity rates and define two effects on the term structure of project-specific GDR.

\footnotetext{
2 The consumption-based approach assumes that a new project is financed by an increase in the savings of the current generation, and an agent's impatience and anticipation regarding the future of the economy determine the discount rate (Ramsey 1928). Notable studies addressing the consumption-based discount rate include Weitzman (2007, 2009, 2012), Gollier (2007, 2008), Grijalva et al. (2014), and Johansson-Stenman and Sterner (2015).

${ }^{3}$ The expected net present value approach claims that the equilibrium economy-wide productivity rate determines the certainty-equivalent discount rate, which is proposed by Weitzman $(1998,2001)$. Papers addressing expected net present value approach include Weitzman (2010), Gollier (2004, 2016a), Hepburn and Groom (2007), Gollier and Weitzman (2010), Traeger (2013), and Freeman and Groom (2015, 2016).
} 


\subsection{Model}

We follow Traeger's (2013) framework to present the GDR. Assume an agent consumes $c_{0}$ units in the present and $c_{t}$ units at date $t$, considering an investment project that reduces current consumption by some certain amount $\epsilon$, which yields an uncertain payoff of $\epsilon F_{t}$ units at time $t$. This project affects the agent's welfare according to:

$$
\Delta w=u\left(c_{0}-\epsilon\right)-u\left(c_{0}\right)+E\left[u\left(c_{t}+\epsilon F_{t}\right)-u\left(c_{t}\right)\right] \exp (-\delta t),
$$

where $u$ is an increasing and concave utility function and $\delta$ is the rate of pure time preference. Therefore, the change in the agent's consumption utility from carrying out the project is

$$
\Delta \pi_{t}=\frac{\Delta w}{u^{\prime}\left(c_{0}\right)}=\left\{-1+E\left[\frac{u^{\prime}\left(c_{t}\right)}{u^{\prime}\left(c_{0}\right)} F_{t}\right] \exp (-\delta t)\right\} \epsilon .
$$

Traeger (2013) defines $\gamma_{t}=\frac{1}{t} \ln \left(1+\frac{\Delta \pi_{t}}{\epsilon}\right)$ as the annual surplus rate and $R_{t}=-\gamma_{t}$ as the GDR:

$$
R_{t}=\delta-\frac{1}{t} \ln E\left[\frac{u^{\prime}\left(c_{t}\right)}{u^{\prime}\left(c_{0}\right)} F_{t}\right] .
$$

Traeger (2013) assumes $F_{t}=e^{r t}$ and $c_{t}=c_{0} e^{g t}$, where $r$ is a project's annual productive rate and $g$ is the annual growth rate of consumption between dates 0 and $t .^{4}$ In this paper, we extend Traeger's theoretical framework to a general situation, where the consumption growth and project productivity rates are time-varying.

The GDR, defined as an annual devaluation rate, measures the present value consumption loss from a productive consumption shift into the future. The corresponding generalized discount factor, $\exp \left(-R_{t} t\right)$, can be explained as follows. The PV of investing an extra unit of productive consumption today that yields $F_{t}$ units at time $t$ equals $\exp \left(-R_{t} t\right)$.

If there exists a complete future market, the GDR of an equilibrium project equals zero. However, long-term risky projects often suffer from non-excludability, non-rivalry, and are not arbitrarily divisible, and future markets are incomplete (Traeger 2013). Therefore, long-term risky projects do not imply a zero GDR. Furthermore, in the setting of incomplete markets, a project's idiosyncratic risk that is uncorrelated with aggregate risk may not be diversified and may have a significant impact on the PV of the project's uncertain benefits. The GDR, as shown in Eq. (3), maps the uncertain benefits to PV and prices the project's idiosyncratic risk. Accordingly, this paper discusses the GDR performance with dual uncertainty due to project productivity and macro consumption growth processes.

\subsection{Relative Wealth Effect and Joint Risk Effect}

We define $g_{t}=\ln c_{t}-\ln c_{t-1}$ as the $\log$ consumption growth rate and $r_{t}=\ln F_{t}-\ln F_{t-1}$ as the log productivity rate of the project from time $t-1$ to $t$. We use a binary random variable, $Y_{t}$, to represent the compound growth process of consumption and project productivity, that is, $Y_{t}=\left(g_{t}, r_{t}\right)^{\prime}$. Furthermore, we introduce the following definition.

\footnotetext{
4 Traeger (2013) proposes the GDR to solve the Weitzman-Gollier puzzle (Weitzman 2001; Gollier 2004). He discusses GDR performance in the case of perfect serial correlation.
} 
Definition 1 The bivariate cumulant-generating function (CGF) $\Psi\left(\theta_{1}, \theta_{2}\right)$ is defined as:

$$
\Psi\left(\theta_{1}, \theta_{2}\right)=\ln E\left[e^{\Theta^{\prime} Y_{t}}\right]=\ln E\left[\left(\frac{c_{t}}{c_{t-1}}\right)^{\theta_{1}}\left(\frac{F_{t}}{F_{t-1}}\right)^{\theta_{2}}\right],
$$

for all $\Theta=\left(\theta_{1}, \theta_{2}\right)^{\prime}$ for which the expectation is finite.

The CGF simplifies the technological side of the model. Based on Martin (2013), when vector $Y_{f}$ follows a binary normal distribution with mean $\left(\mu_{1}, \mu_{2}\right)$ and variance-covariance matrix $\left(\begin{array}{ll}\sigma_{11} & \sigma_{12} \\ \sigma_{12} & \sigma_{22}\end{array}\right)$, the CGF function of $Y_{t}$ can be expressed as:

$$
\Psi\left(\theta_{1}, \theta_{2}\right)=\theta_{1} \mu_{1}+\theta_{2} \mu_{2}+0.5 \theta_{1}^{2} \sigma_{11}+0.5 \theta_{2}^{2} \sigma_{22}+\theta_{1} \theta_{2} \sigma_{12} .
$$

If the compound growth rate $Y_{t}$ follows an independent and identically distributed (i.i.d.) process, the CGF of the $Y_{t}$ can be rewritten as:

$$
\Psi\left(\theta_{1}, \theta_{2}\right)=\frac{\ln E\left[\left(\frac{c_{t}}{c_{0}}\right)^{\theta_{1}}\left(\frac{F_{t}}{F_{0}}\right)^{\theta_{2}}\right]}{t},
$$

for any $t>0$.

For the constant relative risk aversion (CRRA) utility function, that is, $u\left(c_{t}\right)=\frac{c_{t}^{1-\eta}}{1-\eta}$, where $\eta$ is the relative risk aversion coefficient and $\eta>0, \eta \neq 1$, from Eq. (5), the expression of the GDR in Eq. (3) simplifies to:

$$
R_{t}=\delta-\Psi(-\eta, 1)
$$

Therefore, the term structure of the GDR is completely flat for the CRRA utility function combined with an i.i.d. process. In fact, if $Y_{t}$ follows an i.i.d. normal process, from Eqs. (4) and (6), the expression of the GDR, $R_{t}$, can be written as follows:

$$
R_{t}=\delta+\underbrace{\eta \mu_{1}-\mu_{2}}_{\text {relative wealth effect }} \underbrace{-\frac{1}{2} \eta^{2} \sigma_{11}-\frac{1}{2} \sigma_{22}+\eta \sigma_{12}}_{\text {joint risk effect }},
$$

where $\mu_{1}$ and $\mu_{2}$ are the expectations of $g_{t}$ and $r_{t}$, respectively. $\sigma_{11}, \sigma_{22}$, and $\sigma_{12}$ are the elements of the variance-covariance matrix of the joint growth process.

The first three terms capture the difference between the simple consumption-side Ramsey discount rate and the project's expected productivity rate. In particular, the second term $\eta \mu_{1}$ is referred to as a "wealth effect" that reflects the future wealth level of the entire economy, ${ }^{5}$ and $\mu_{2}$ in the third term reflects the future wealth level of the project. Therefore, we call the combined second and third terms as the "relative wealth effect".

The last three terms capture the joint risk from dual uncertainty of consumption growth and a project's productivity. We call the last three terms as the "joint risk effect". Both the variance of the consumption growth rate and the project's productivity rate reduce the GDR. If the productivity rate is positively (negatively) related to the consumption growth

\footnotetext{
5 An increase in the consumption growth rate makes an agent reluctant to sacrifice present consumption to improve the future, which is already better than the present (Gollier 2012).
} 
rate, the covariance of the consumption growth rate and the project's productivity rate increases (decreases) the GDR.

An i.i.d. process implies that the compound growth rate contains no serial correlation and the previous stages' growth rate provides no information about the future growth rate. However, any model of long-term economic growth should recognize the persistence of shocks at different frequencies (Gollier 2014). Indeed, many empirical studies on discount rates focus on how the persistence in uncertainty regarding the discount rate affects the certainty-equivalent discount rate (Newell and Pizer 2003; Groom et al. 2007; Gollier et al. 2008; Hepburn et al. 2009; Freeman et al. 2015). These studies show that the persistence of shocks on economic growth increase the long-term macroeconomic uncertainty. Thus, in the next section we analyse the term structure of the GDR under an evolution process with persistent shocks.

\section{GDR Term Structure}

Here, we investigate how the relative wealth effect and joint risk effect form the shape of the term structure of the GDR and compare the GDR approach with the RADR approach.

\subsection{GDR Under a Process with Persistent Shocks}

Frequently, the economic growth in a given year is affected by that in the previous year or even that in past years. Due to the economic cycle, economic growth may present a phenomenon of regression to the mean. For example, although the GDP growth rate in China has remained at about $7 \%$ in recent years, such a high growth rate cannot be sustained for a long time. The reason may be the diminishing returns to capital and labour inputs, which allow the economy to adapt to a lower or more reasonable growth rate. In this section, we assume that the consumption growth and project productivity rates follow mean-reverting processes.

Following Bansal and Yaron (2004), we use a stochastic process with persistent shocks to describe the mean-reverting process of consumption growth:

$$
\begin{aligned}
& g_{t}=\mu_{1}+y_{t}+\varepsilon_{g t} \\
& y_{t}=\phi y_{t-1}+\varepsilon_{y t} \\
& \varepsilon_{g t} \sim N . i . i . d .\left(0, \sigma_{g}^{2}\right), \varepsilon_{y t} \sim N . i . i . d .\left(0, \sigma_{y}^{2}\right),
\end{aligned}
$$

where parameter $\mu_{1}$ is the historical mean of $g_{t}$. Variable $y_{t}$ is a persistent component with an initial state $y_{-1}$, and its degree of persistence is represented by parameter $\phi$, which takes values between 0 and 1 . If $\phi=0$, the model reverts to a pure random walk. If $y_{-1}=0$, the expectation of the consumption growth rate equals its historical mean.

Similarly, we assume that the project's productivity rate also contains persistent components and follows a mean-reverting process:

$$
\begin{aligned}
& r_{t}=\mu_{2}+\xi_{t}\left(\alpha_{t} y_{t}+\left(1-\alpha_{t}\right) i_{t}\right)+\varepsilon_{r t} \\
& i_{t}=i_{t-1}+\varepsilon_{i t} \\
& \varepsilon_{r t} \sim N . i . i . d .\left(0, \sigma_{r}^{2}\right), \varepsilon_{i t} \sim N . i . i . d .\left(0, \sigma_{i}^{2}\right),
\end{aligned}
$$

where parameter $\mu_{2}$ is the historical mean of $r_{t}$. Variable $i_{t}$ with initial state $i_{-1}$ is the idiosyncratic persistent component of the project's productivity rate, which is independent of 
$y_{t}$. Parameter $\xi_{t}$ represents the intensity of total persistent shocks to the project's productivity rate. The total persistent shocks are assumed to be a weighted sum of persistent consumption growth shocks and persistent idiosyncratic shocks, the weight associated to persistent consumption growth shocks being $\alpha_{t}$. If $\alpha_{t}=1$, all persistent shocks to the project's productivity rate stem from the consumption growth process, and the project's idiosyncratic risk comes from a transitory shock $\varepsilon_{r t}$. If $\alpha_{t}=0$, the project's productivity rate has nothing to do with the business cycle. There is no reason $\xi_{t}$ and $\alpha_{t}$ should be constant over time. We could proceed with a general analysis of GDR in terms of time-varying $\xi_{t}$ and $\alpha_{t}$. However, in order to identify the impact of idiosyncratic risk on the GDR more concisely, we assume that these two parameters are constant in the following discussion.

To obtain the analytic expression of the GDR, we denote $X_{t}$ and $Z_{t}$ as the cumulative consumption growth and productivity rates, respectively:

$$
X_{t}=\sum_{\tau=0}^{t-1} g_{\tau}, \quad Z_{t}=\sum_{\tau=0}^{t-1} r_{\tau} .
$$

From Definition 1 in Sect. 2.2, the CGF of $\left(X_{t}, Z_{t}\right)$ is $\Psi_{\left(X_{t}, Z_{t}\right)}\left(\theta_{1}, \theta_{2}\right)=\ln E\left[e^{\theta_{1} X_{t}+\theta_{2} Z_{t}}\right]$. The GDR defined by Eq. (3) can therefore be rewritten as:

$$
R_{t}=\delta-\frac{\Psi_{\left(X_{t}, Z_{t}\right)}(-\eta, 1)}{t} .
$$

By carefully iterating and summing Eq. (10) and using the expression of CGF in Eq. (4), we obtain the following proposition.

Proposition 1 If the consumption growth and project productivity rates follow a meanreverting process with persistent shocks [i.e., Eqs. (8)-(9)], the corresponding GDR is:

$$
R_{t}=\delta+D(t)+V(t)
$$

where

$$
D(t)=\eta \mu_{1}-\mu_{2}-\xi(1-\alpha) i_{-1}+(\eta-\xi \alpha) y_{-1} \frac{\phi}{1-\phi} \frac{1-\phi^{t}}{t}
$$

and

$$
\begin{aligned}
V(t)= & -\left(\frac{\eta^{2}}{2}+\frac{\xi^{2} \alpha^{2}}{2}-\eta \xi \alpha\right) \sigma_{g}^{2}-\frac{1}{2} \sigma_{r}^{2}-\left(\frac{\eta^{2}}{2}+\xi^{2} \alpha^{2}-\eta \xi \alpha\right) \frac{\sigma_{y}^{2}}{(1-\phi)^{2}} \\
& +\left(\frac{\eta^{2}}{2}+\xi^{2} \alpha^{2}-\eta \xi \alpha\right) \frac{\sigma_{y}^{2}}{(1-\phi)^{2}}\left[\frac{2 \phi}{1-\phi} \frac{1-\phi^{t}}{t}-\frac{\phi^{2}}{1-\phi^{2}} \frac{1-\phi^{2 t}}{t}\right]-\frac{1}{2} \xi^{2}(1-\alpha)^{2} \frac{t^{2}}{3} \sigma_{i}^{2}
\end{aligned}
$$

Proof See "Appendix 1".

Proposition 1 provides the analytical expression of the GDR under a mean-reverting process with persistent shocks. The GDR is the sum of the rate of pure time preference $\delta$, relative wealth effect term $D(t)$, and joint risk effect term $V(t)$. Next, we analyse the term structure of $D(t)$ and $V(t)$.

The relative wealth effect contains four constant terms and a time-varying term, i.e., $(\eta-\xi \alpha) y_{-1} \frac{\phi}{1-\phi} \frac{1-\phi^{t}}{t}$, which is caused by the persistent consumption growth component. 
When the economy is booming and the diminishing speed of $E\left[r_{t}\right]$ is slower than that of $E\left[\eta g_{t}\right]$ (i.e., $y_{-1}>0$ and $\xi \alpha<\eta$ ), or when the economy is in a downturn and the rising speed of $E\left[r_{t}\right]$ is faster than that of $E\left[\eta g_{t}\right]$ (i.e., $y_{-1}<0$ and $\xi \alpha>\eta$ ), the relative wealth effect term decreases over time. ${ }^{6}$ As a result, the relative wealth effect tends to reduce the GDR. By contrast, if $y_{-1}>0$ and $\xi \alpha>\eta$ or if $y_{-1}<0$ and $\xi \alpha<\eta$, the relative wealth effect tends to raise the GDR.

The joint risk effect contains three constant terms and two time-varying terms. Because both $\frac{2 \phi}{1-\phi} \frac{1-\phi^{t}}{t}-\frac{\phi^{2}}{1-\phi^{2}} \frac{1-\phi^{2 t}}{t}$ and $-\frac{1}{2} \xi^{2}(1-\alpha)^{2} \frac{t^{2}}{3} \sigma_{i}^{2}$ decrease over time, the joint risk effect tends to reduce the GDR. The reason is that the joint risk in consumption growth and productivity tends to raise an agent's willingness to sacrifice present consumption to improve the future.

The term structure of the GDR is determined by the way the relative wealth effect and the joint risk effect evolve with the time horizon. A declining GDR assigns a higher weight to future benefits and costs than a constant GDR. If the relative wealth effect and the joint risk effect both tend to reduce the GDR, the GDR decreases over time. If the relative wealth effect tends to raise the GDR and the joint risk effect dominates the relative wealth effect, the GDR also decreases over time. The following proposition provides a sufficient condition for a decreasing term structure of the GDR.

Proposition 2 If the consumption growth and project productivity rates follow a meanreverting process with persistent shocks [i.e., Eqs. (8)-(9)] and the corresponding parameters satisfy

$$
(\eta-\xi \alpha) y_{-1} \frac{\phi}{1-\phi}>-\left(\eta^{2}+2 \xi^{2} \alpha^{2}-2 \eta \xi \alpha\right) \frac{\phi}{1+\phi} \frac{\sigma_{y}^{2}}{(1-\phi)^{2}}-\xi^{2}(1-\alpha)^{2} \frac{\sigma_{i}^{2}}{\phi \ln ^{2} \phi},
$$

the GDR, i.e., $R_{t}$, decreases over time.

\section{Proof See "Appendix 2".}

We illustrate the results of Proposition 2 with a numerical example. We calibrate the model at the annual frequency. We assume $\delta=0.011$, and $\eta=1.35$, which matches the results of Drupp et al. (2018) that surveyed around 200 discounting experts. ${ }^{7}$ Following Bansal and Yaron (2004), we choose $\mu_{1}=0.018, \sigma_{g}=0.027, \sigma_{y}=0.0012,{ }^{8}$ and $\phi=0.979$. Without loss of generality, we choose $\mu_{2}=0.034, \sigma_{r}=0.031$, and $i_{-1}=0$. Furthermore, we assume that the economy is booming with $y_{-1}=0.012$ (Gollier 2012) and choose $\sigma_{i}=0.0005, \xi=1.69$, and $\alpha=0.8$ to satisfy the inequality (14) in Proposition 2. Figure 1 plots the GDR, which decreases over time.

Remarkably, the inequality (14) in Proposition 2 is a sufficient but not necessary condition for the GDR to be monotonically decreasing. For example, if $\xi \alpha>\eta$ and the economy

\footnotetext{
6 This result holds because $\frac{1-\phi^{t}}{t}$ monotonically decreases over time.

7 There is substantial disagreement over the two central normative parameters, the pure rate of time preference $\delta$ and elasticity of marginal utility $\eta$ ( $\eta$ is the relative risk aversion coefficient under CRRA). For example, Tol (2010) estimates parameter $\eta$ to be 0.7. However, Groom and Maddison (2019) suggest $\eta$ is 1.5 for the United Kingdom.

8 The original parameter calibration values of the consumption growth rate employed in Bansal and Yaron (2004) are monthly. Here, we convert them to annual calibration values.
} 


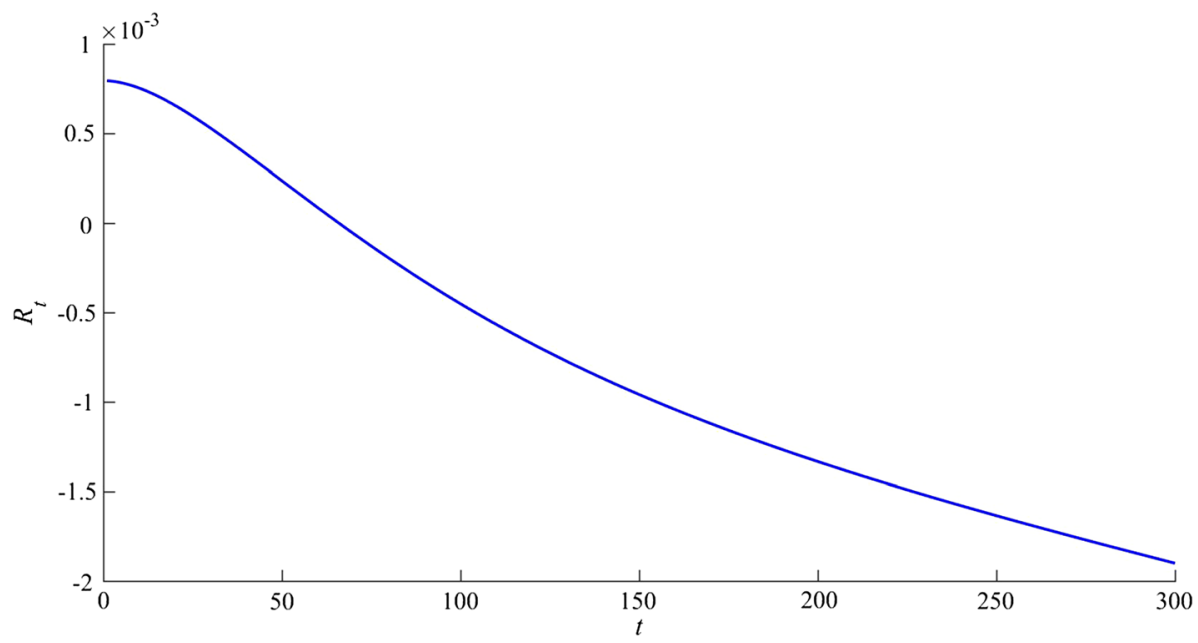

Fig. 1 The generalized discount rate as a function of maturity

is booming, the GDR may have an increasing term structure for small maturities (see “Appendix 3").

\subsection{Relationship Between the GDR and RADR Approaches}

The RADR, which is based on the CCAPM, is a classical approach for evaluating risky projects. We here compare the GDR with the RADR.

If we use the RADR approach to evaluate the PV of a future uncertain benefit $F_{t}$, it requires a two-step procedure. The first step is to calculate the expectation of uncertain benefit, $E\left[F_{t}\right]$. The second step is to calculate the PV of $E\left[F_{t}\right]$ by using the RADR which is denoted as $\rho_{t}$, where $P V=e^{-\rho_{t} t} E\left[F_{t}\right]$ with $\rho_{t}=\delta-\frac{1}{t} \ln \frac{E\left[F_{t} u^{\prime}\left(c_{t}\right)\right]}{u^{\prime}\left(c_{0}\right) E\left[F_{t}\right]}$. In the RADR literature (Gollier 2014, 2016b; Dietz et al. 2018), the uncertain benefits of risky projects are assumed to be:

$$
E\left[F_{t} \mid c_{t}\right]=c_{t}^{\beta},
$$

where $\beta$ is the elasticity of the benefits of changes in aggregate consumption. Combined with the assumption of Eq. (15), the RADR is determined by the consumption growth process and the covariance of a project's benefit payoffs with the aggregate consumption. The project's idiosyncratic risk, which is assumed to be diversified, is not priced. ${ }^{9}$

Alternatively, if we use the GDR approach, the PV of $F_{t}$ is equal to $e^{-R_{t} t}=E\left[\frac{u^{\prime}\left(c_{t}\right)}{u^{\prime}\left(c_{0}\right)} F_{t}\right] e^{-\delta t}$. To identify the main difference between these two approaches, from the definition of the project's productivity rate and Eq. (9), we rewrite the benefits $F_{t}$ as follows:

\footnotetext{
${ }_{9}$ According to the CCAPM (Lucas 1978), the ratio of marginal consumption utility in different periods/ states is equal to the relative price, which depends on aggregate consumption. Therefore, the project's idiosyncratic risk should not be priced.
} 


$$
F_{t}=\left[\varphi\left(\varepsilon_{i t}\right)\right]^{\xi(1-\alpha)} c_{t}^{\xi \alpha} \psi(t)
$$

where $\varphi\left(\varepsilon_{i t}\right)$ is independent of $c_{t}$, and $\psi(t)$ is determined by the historical means $\mu_{1}, \mu_{2}$, transitory shocks $\varepsilon_{g t}$ and $\varepsilon_{r t}{ }^{10}$ In particular, if the project productivity process matches the macro consumption growth process, i.e., $\psi(t)=1$, from Eq. (16), we get

$$
E\left[F_{t} \mid c_{t}\right]=c_{t}^{\xi \alpha}
$$

which means $\xi \alpha$ equals the CCAPM $\beta$. Therefore, the intensity of persistent consumption growth shocks can be referred to as the elasticity of the net benefit to changes in aggregate consumption if $\psi(t)=1$.

In a complete future market, the project's idiosyncratic risk is diversifiable, and the GDR and RADR frameworks are equivalent. Mathematically, $e^{-R_{t} t}=e^{-\rho_{t} t} E\left[F_{t}\right]$. This can be expressed as:

$$
R_{t}=\rho_{t}-\frac{1}{t} \ln E\left[F_{t}\right]
$$

The GDR captures the difference between the RADR and the average annual project productivity rate. For an equilibrium project in a complete future market, the RADR equals the average annual productivity rate of the project, while the corresponding GDR equals zero.

However, if the project cannot be marketed in an incomplete market, its idiosyncratic risk should be priced. For example, if the project's productivity rate is affected by the persistent idiosyncratic shocks i.e., $\alpha \neq 1$, the idiosyncratic risk cannot be diversifiable and affects the PV of the project's future uncertain benefits. This scenario is not analysed in the existing literature on RADR. However, the GDR approach includes the analysis of this scenario. As shown in Eq. (13), the component $-\frac{1}{2} \xi^{2}(1-\alpha)^{2} \frac{t^{2}}{3} \sigma_{i}^{2}$ measures the impact of the nondiversifiable idiosyncratic risk. The impact of nondiversifiable idiosyncratic risk on the PV of future benefits could be quite pronounced, as a numerical application in the next section will demonstrate.

\section{Numerical Application}

In this section, we use emissions reduction projects to numerically analyse how nondiversifiable idiosyncratic risk affects the GDR. We further analyse the impact of $\xi \alpha$ on the PV of a project's future uncertain benefits. For brevity, in this section, we use the term "climate beta" to denote the product of parameters $\xi$ and $\alpha$.

Emissions reduction projects are "green investments" to mitigate climate change. They are affected by climate change and long-term economic development. Inspired by the widespread dynamic integrated model of climate and the economy (DICE) model (Nordhaus 2008, 2018), for an emissions reduction project, we assume that persistent consumption growth shocks stem from economic output growth and that persistent idiosyncratic shocks stem from climate sensitivity changes. We choose $\alpha=1$ to denote the setting of a complete market $(\mathrm{CM})$. Since the idiosyncratic risk cannot be diversified away when

$\overline{{ }^{10} \text { Here, } \varphi\left(\varepsilon_{i t}\right)=\exp \left[t i_{-1}+\sum_{\tau=0}^{t-1}(t-\tau) \varepsilon_{i \tau}\right], \psi(t)=\frac{F_{0} \exp \left(\mu_{2} t+\sum_{\tau=0}^{t} \varepsilon_{r \tau}\right)}{c_{0} \exp \left[\xi \alpha\left(\mu_{1} t+\sum_{\tau=0}^{t} \varepsilon_{g \tau}\right)\right]}}$. 


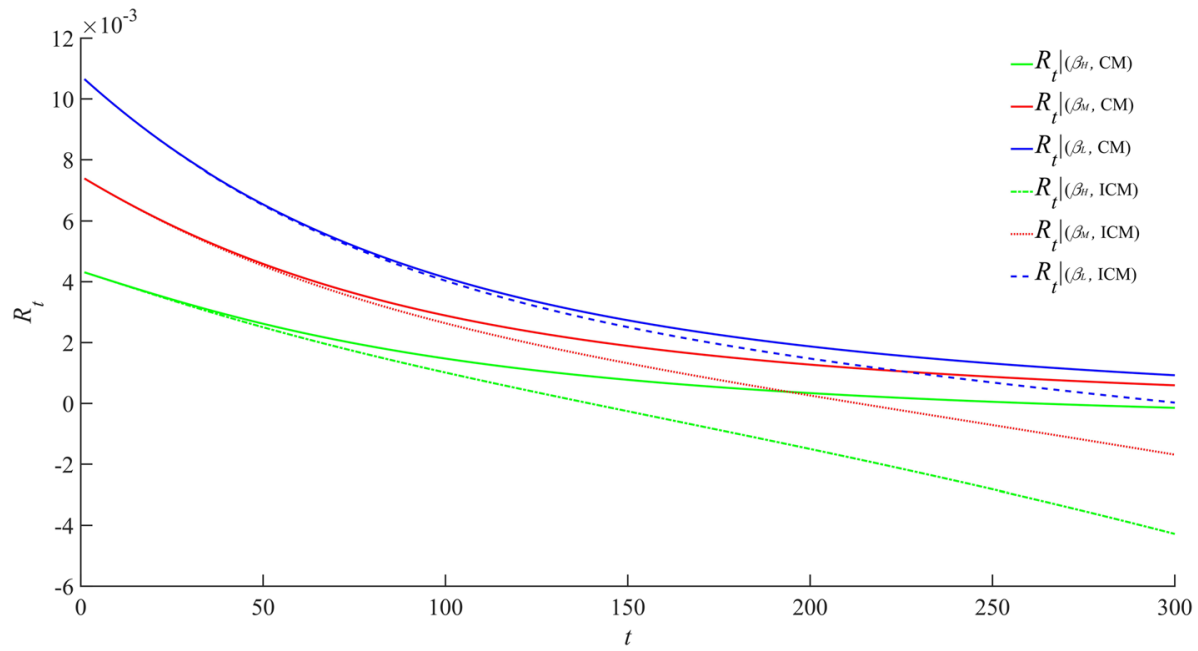

Fig. 2 The generalized discount rate of the emissions reduction project as a function of the maturity for different climate betas in different scenarios

there exist persistent idiosyncratic shocks (i.e., $0<\alpha<1$ ), without loss of generality, we choose $\alpha=0.5$ to denote the setting of an incomplete market (ICM). Furthermore, based on the estimate of climatic beta in Dietz et al. (2018), we choose $\beta_{H}=1.05, \beta_{M}=0.78$, and $\beta_{L}=0.49$ with $\xi \alpha=\beta$, where $\beta_{H}, \beta_{M}$ and $\beta_{L}$ correspond to the high-beta, medium-beta, and low-beta projects, respectively. Figure 2 plots the GDR for three types of emissions reduction projects in two scenarios: CM and ICM. ${ }^{11}$

Figure 2 shows that the GDR in the setting of incomplete markets (dotted lines) is smaller than that in the setting of complete markets (solid lines) for projects with the same climate beta. Therefore, the PV of climate mitigation in the setting of incomplete markets is larger than that in the setting of complete markets. That is, the PV of the emissions reduction benefits is underestimated when ignoring the impact of nondiversifiable idiosyncratic risk. The economic intuition can be explained as follows. The benefits of emissions abatement include monetary and non-monetary benefits. The monetary benefits increase future consumption, and their PV depends on the climate beta. The non-monetary benefits improve the quality of the ecological environment, and their PV depends on the relative price of the environmental quality. ${ }^{12}$ Since persistent idiosyncratic shocks associated with climate sensitivity increase the relative price of environmental quality, the PV of the nonmonetary benefits of emissions abatement is underestimated when ignoring the impact of persistent idiosyncratic shocks.

From Fig. 2, the higher the climate beta, the smaller the GDR, which is consistent with the results of Dietz et al. (2018). ${ }^{13}$ That is to say, the higher the intensity of the persistent consumption growth shocks, the greater the PV of climate mitigation.

\footnotetext{
11 The settings for the other parameters are the same as that in Sect. 3.1.

12 The relative price of the environmental quality is measured by the degree of substitutability of natural capital in the ecological discount rate literature (Hoel and Sterner 2007; Gollier 2010, 2019).

13 Dietz et al. (2018) point out that the social cost of carbon increases with the climate beta.
} 


\section{Conclusions}

In this study, we use the GDR model to analyse how aggregate risk and nondiversifiable idiosyncratic risk effect the evaluation of long-term risky projects. We incorporate the persistent shocks of the consumption growth and the project's productivity rates into our model, and further investigate the term structure of the GDR. A numerical application is presented to illustrate our findings.

Our main results are as follows. First, the term structure of the GDR is determined by the relative wealth and joint risk effects. The relative wealth effect tends to increase (reduce) the GDR if a high (low) social wealth growth is accompanied with a low (high) project productivity, while the joint risk effect tends to reduce it. The GDR decreases over time unless the increasing trend due to the relative wealth effect dominates the joint risk effect. Second, we find that, the nondiversifiable idiosyncratic risk reduces the GDR and raises the PV of the project's future uncertain benefits. Third, a numerical application demonstrates that the PV of the emissions reduction benefits is underestimated when ignoring the impact of persistent idiosyncratic shocks associated with climate sensitivity.

Two possible extensions of the model could be interesting as a scope for future research. First, while the simplified constant $\xi$ and constant $\alpha$ could concisely explain the impact of the project's idiosyncratic risk on the discount rate, the time-varying $\xi_{t}$ and $\alpha_{t}$ is more rational. Therefore, we could study the GDR with time-varying $\xi_{t}$ and $\alpha_{t}$. Second, as our model theoretically quantifies the impact of the risk characteristics of future benefits on the discount rate, future research may consider how the central novel parameters $\xi$ and $\alpha$ could be estimated empirically.

Acknowledgements We would like to thank the editor Thomas Sterner and the two very constructive referees for their extremely helpful comments. This work is supported by the National Natural Science Foundation of China (Grant Numbers 71521061, 71790593, 71972066, 71850012), and the China Postdoctoral Science Foundation (Grant Number 2018M642978).

Open Access This article is licensed under a Creative Commons Attribution 4.0 International License, which permits use, sharing, adaptation, distribution and reproduction in any medium or format, as long as you give appropriate credit to the original author(s) and the source, provide a link to the Creative Commons licence, and indicate if changes were made. The images or other third party material in this article are included in the article's Creative Commons licence, unless indicated otherwise in a credit line to the material. If material is not included in the article's Creative Commons licence and your intended use is not permitted by statutory regulation or exceeds the permitted use, you will need to obtain permission directly from the copyright holder. To view a copy of this licence, visit http://creativecommons.org/licenses/by/4.0/.

\section{Appendix 1: Proof of Proposition 1}

From the definitions of $X_{t}$ and $Z_{t}$,

$$
X_{t}=\mu_{1} t+y_{-1} \phi \frac{1-\phi^{t}}{1-\phi}+\sum_{\tau=0}^{t-1}\left(\frac{1-\phi^{t-\tau}}{1-\phi} \varepsilon_{y \tau}+\varepsilon_{g \tau}\right)
$$

and

$$
Z_{t}=\mu_{2} t-\xi \alpha \mu_{1} t+\xi \alpha X_{t}+\sum_{\tau=0}^{t-1} \varepsilon_{r \tau}-\xi \alpha \sum_{\tau=0}^{t-1} \varepsilon_{g \tau}+\xi(1-\alpha)\left(t i_{-1}+\sum_{\tau=0}^{t-1}(t-\tau) \varepsilon_{i \tau}\right),
$$


where $\varepsilon_{y \tau}, \varepsilon_{g \tau}, \varepsilon_{r \tau}$ and $\varepsilon_{i \tau}$ are assumed to be normally distributed, it is easy to see that:

$$
X_{t} \sim N\left(a_{1}, b_{1}^{2}\right)
$$

where $a_{1}=\mu_{1} t+y_{-1} \phi \frac{1-\phi^{t}}{1-\phi}$ and $b_{1}^{2}=\frac{\sigma_{y}^{2}}{(1-\phi)^{2}}\left[t-2 \phi \frac{1-\phi^{t}}{1-\phi}+\phi^{2} \frac{1-\phi^{2 t}}{1-\phi^{2}}\right]+t \sigma_{g}^{2}$. Furthermore, $Z_{t}$ is also a normally distributed variable conditional on $X_{t}$,

$$
Z_{t} \mid X_{t} \sim N\left(a_{2}+\xi X_{t}, b_{2}^{2}\right)
$$

where $a_{2}=\mu_{2} t-\xi \alpha \mu_{1} t+\xi(1-\alpha) i_{-1} t$ and $b_{2}^{2}=t \sigma_{r}^{2}+\xi^{2} \alpha^{2} b_{1}^{2}+\xi^{2} \alpha^{2} \sigma_{g}^{2} t+\xi^{2}(1-\alpha)^{2} \frac{t^{3}}{3} \sigma_{i}^{2}$.

Stochastic processes (19)-(20) are sufficient for the analysis in a reduced form. The probability density function of $X_{t}$ is of the form $f_{X_{t}}(x)=\frac{1}{\sqrt{2 \pi} b_{1}} e^{-\frac{\left(x-a_{1}\right)^{2}}{2 b_{1}^{2}}}$ and the conditional probability density function for the random variable $Z_{t}$ is of the form $f_{Z_{t} \mid X_{t}}(z \mid x)=\frac{1}{\sqrt{2 \pi} b_{2}} e^{-\frac{\left(z-a_{2}-\xi \alpha x\right)^{2}}{2 b_{2}^{2}}}$. Therefore, the joint probability density function of $\left(X_{t}, Z_{t}\right)$ is of the form

$$
f(x, z)=\frac{1}{2 \pi b_{1} \sqrt{\xi^{2} b_{1}^{2}+b_{2}^{2}} \frac{b_{2}}{\sqrt{\xi^{2} b_{1}^{2}+b_{2}^{2}}}} \exp [g(x, z)],
$$

where $g(x, z)=-\frac{1}{2 \frac{b_{2}^{2}}{\xi^{2} b_{1}^{2}+b_{2}^{2}}}\left(\frac{\left(x-a_{1}\right)^{2}}{b_{1}^{2}}-2 \frac{\xi b_{1}}{\sqrt{\xi^{2} b_{1}^{2}+b_{2}^{2}}} \frac{\left(x-a_{1}\right)\left(z-a_{2}-\xi \alpha a_{1}\right)}{b_{1} \sqrt{\xi^{2} b_{1}^{2}+b_{2}^{2}}}+\frac{\left(z-a_{2}-\xi \alpha a_{1}\right)^{2}}{\xi^{2} b_{1}^{2}+b_{2}^{2}}\right)$.

We denote $\left(X_{t}, Z_{t}\right) \sim N\left(\tilde{\mu_{1}}, \tilde{\mu_{2}}, \tilde{\sigma_{1}^{2}}, \tilde{\sigma_{2}^{2}}, \rho\right)$. From $\quad$ Eq. (21), we obtain $\tilde{\mu_{1}}=a_{1}, \tilde{\mu_{2}}=\xi \alpha a_{1}+a_{2}, \tilde{\sigma_{1}^{2}}=b_{1}^{2}, \tilde{\sigma}_{2}^{2}=\xi^{2} \alpha^{2} b_{1}^{2}+b_{2}^{2}$, and $\rho=\frac{\xi \alpha b_{1}}{\sqrt{\xi^{2} \alpha^{2} b_{1}^{2}+b_{2}^{2}}}$. Then, the elements of the covariance matrix of joint growth process $\left(X_{t}, Z_{t}\right)$ are $\sigma_{11}=b_{1}^{2}, \sigma_{12}=\xi \alpha b_{1}^{2}$, $\sigma_{21}=\xi \alpha b_{1}^{2}$, and $\sigma_{22}=\xi^{2} \alpha^{2} b_{1}^{2}+b_{2}^{2}$, which means

$$
\Psi_{\left(X_{t}, Z_{t}\right)}(-\eta, 1)=(\xi \alpha-\eta) a_{1}+a_{2}+\left(\frac{\eta^{2}}{2}+\frac{\xi^{2} \alpha^{2}}{2}\right) b_{1}^{2}+\frac{1}{2} b_{2}^{2}-\eta \xi \alpha b_{1}^{2} .
$$

Because $R_{t}=\delta-\frac{\Psi_{\left(X_{t}, Z_{t}\right)}(-\eta, 1)}{t}$, from Eq. (22), we obtain Proposition 1 .

\section{Appendix 2: Proof of Proposition 2}

From the expression of $R_{t}$, we denote

$$
R_{t}=f_{c}+f_{1} \frac{1-\phi^{t}}{t}+f_{2} \frac{1-\phi^{2 t}}{t}+f_{3} t^{2}
$$

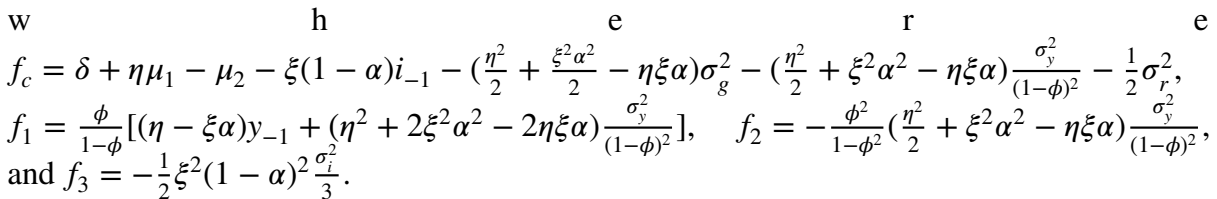

From Eq. (23), we have 


$$
\frac{d R_{t}}{d t}=f_{1} \frac{-\phi^{t} t \ln \phi-1+\phi^{t}}{t^{2}}+f_{2} \frac{-2 \phi^{2 t} t \ln \phi-1+\phi^{2 t}}{t^{2}}+2 f_{3} t
$$

We nextly give a sufficient condition for $\frac{d R_{t}}{d t}<0$. Let $g(t)=f_{1}\left(-\phi^{t} t \ln \phi-1+\phi^{t}\right)+f_{2}\left(-2 \phi^{2 t} t \ln \phi-1+\phi^{2 t}\right)+2 f_{3} t^{3}$. Then, we obtain $g(0)=0, g^{\prime}(t)=\left[-\left(f_{1}+4 f_{2} \phi^{t}\right) \phi^{t} \ln ^{2} \phi+6 f_{3} t\right] t$. Because $f_{2}<0$ and $\phi^{t}<1$ for $t>0$, we have $f_{2} \phi^{t}>f_{2}$, and therefore,

$$
g^{\prime}(t)<\left[-\left(f_{1}+4 f_{2}\right)+6 \frac{f_{3}}{\ln ^{2} \phi} \frac{t}{\phi^{t}}\right] t .
$$

Because $\frac{t}{\phi^{t}}>\frac{1}{\phi}$ for $t>0$, from Eq. (25), we obtain $g^{\prime}(t)<0$ if

$$
f_{1}+4 f_{2}>\frac{6 f_{3}}{\ln ^{2} \phi} \frac{1}{\phi}
$$

By combining Eq. (26) with the expressions for $f_{1}, f_{2}$ and $f_{3}$, we have $g(t)<0$ for $t>0$ if

$$
(\eta-\xi \alpha) y_{-1} \frac{\phi}{1-\phi}>-\left(\eta^{2}+2 \xi^{2} \alpha^{2}-2 \eta \xi \alpha\right) \frac{\phi}{1+\phi} \frac{\sigma_{y}^{2}}{(1-\phi)^{2}}-\xi^{2}(1-\alpha)^{2} \frac{\sigma_{i}^{2}}{\phi \ln ^{2} \phi} .
$$

From the definition of $g(t)$ and Eq. (24), the inequality (27) is a sufficient condition for a decreasing term structure of $R_{t}$.

\section{Appendix 3: Proof of the Monotonicity of $R(t)$ for Small Maturities}

From Eq. (24) in "Appendix 2", we have

$$
\lim _{t \rightarrow 0} \frac{d R_{t}}{d t}=-\left(f_{1}+4 f_{2}\right) \frac{1}{2} \ln ^{2} \phi .
$$

By combining Eq. (28) with the expressions of $f_{1}$ and $f_{2}$ defined in "Appendix 2", we find that $f_{1}+4 f_{2}<0$ if

$$
\frac{\eta-\xi \alpha}{\eta^{2}+2 \xi^{2} \alpha^{2}-2 \eta \xi \alpha} y_{-1}<-\frac{\sigma_{y}^{2}}{1-\phi^{2}} .
$$

Therefore, if the parameters satisfy the inequality (29), from Eq. (28), $R_{t}$ increases in small maturities.

\section{References}

Arrow KJ, Cropper ML, Gollier C, Groom B, Heal GM, Newell RG, Nordhaus WD, Pindyck RS, Pizer WA, Portney PR, Sterner T, Tol RSJ, Weitzman ML (2013) Determining benefits and costs for future generations. Science 341:349-350

Arrow KJ, Cropper ML, Gollier C, Groom B, Heal GM, Newell RG, Nordhaus WD, Pindyck RS, Pizer WA, Portney PR, Sterner T, Tol RSJ, Weitzman ML (2014) Should governments use a declining discount rate in project analysis? Rev Environ Econ Policy 8:145-163 
Bansal R, Yaron A (2004) Risks for the long run: a potential resolution of asset pricing puzzles. J Finance 59:1481-1509

Cropper ML, Freeman MC, Groom B, Pizer WA (2014) Declining discount rates. Am Econ Rev 104:538-543

Dietz S, Gollier C, Kessler L (2018) The climate beta. J Environ Econ Manag 87:258-274

Drupp MA, Freeman MC, Groom B, Nesje F (2018) Discounting disentangled. Am Econ J Econ Policy 10:109-134

Freeman MC, Groom B (2015) Positively gamma discounting: combining the opinions of experts on the social discount rate. Econ J 125:1015-1024

Freeman MC, Groom B (2016) How certain are we about the certainty-equivalent long term social discount rate? J Environ Econ Manag 79:152-168

Freeman MC, Groom B, Panopoulou E, Pantelidis T (2015) Declining discount rates and the Fisher effect: inflated past, discounted future? J Environ Econ Manag 73:32-49

Gollier C (2004) Maximizing the expected net future value as an alternative strategy to gamma discounting. Finance Res Lett 1:85-89

Gollier C (2007) The consumption-based determinants of the term structure of discount rate. Math Financ Econ 1:81-101

Gollier C (2008) Discounting with fat-tailed economic growth. J Risk Uncertain 37:171-186

Gollier C (2010) Ecological discounting. J Econ Theory 145:812-829

Gollier C (2012) Pricing the planet's future: the economics of discounting in an uncertain world. Princeton University Press, Princeton

Gollier C (2014) Discounting and growth. Am Econ Rev 104:534-537

Gollier C (2016a) Gamma discounters are short-termist. J Public Econ 142:83-90

Gollier C (2016b) Evaluation of long-dated assets: the role of parameter uncertainty. J Monet Econ 84:66-83

Gollier C (2019) Valuation of natural capital under uncertain substitutability. J Environ Econ Manag 94:54-66

Gollier C, Weitzman ML (2010) How should the distant future be discounted when discount rates are uncertain? Econ Lett 107:350-353

Gollier C, Koundouri P, Pantelidis T (2008) Declining discount rates: economic justifications and implications for long-run policy. Econ Policy 23:758-795

Grijalva TC, Lusk JL, Shaw WD (2014) Discounting the distant future: an experimental investigation. Environ Resour Econ 59:39-63

Groom B, Maddison D (2019) New estimates of the elasticity of marginal utility for the UK. Environ Resour Econ 72:1155-1182

Groom B, Hepburn C, Koundouri P, Pearce D (2005) Declining discount rates: the long and the short of it. Environ Resour Econ 32:445-493

Groom B, Koundouri P, Panopoulou E, Pantelidis T (2007) Discounting the distant future: how much does model selection affect the certainty equivalent rate? J Appl Econom 22:641-656

Hepburn C, Groom B (2007) Gamma discounting and expected net future value. J Environ Econ Manag 53:99-109

Hepburn C, Koundouri P, Panopoulou E, Pantelidis T (2009) Social discounting under uncertainty: a crosscountry comparison. J Environ Econ Manag 57:140-150

Hoel M, Sterner T (2007) Discounting and relative prices. Clim Change 84:265-280

Johansson-Stenman O, Sterner T (2015) Discounting and relative consumption. J Environ Econ Manag 71:19-33

Lucas RE (1978) Asset prices in an exchange economy. Econometrica 46:1429-1445

Martin I (2013) The Lucas orchard. Econometrica 81:55-111

Newell RG, Pizer WA (2003) Discounting the distant future: how much do uncertain rates increase valuations? J Environ Econ Manag 46:52-71

Nordhaus W (2008) A question of balance: economic modeling of global warming. Yale University Press, New Haven (online preprint: a question of balance: weighing the options on global warming policies)

Nordhaus W (2018) Projections and uncertainties about climate change in an era of minimal climate policies. Am Econ J Econ Policy 10:333-360

Ramsey FP (1928) A mathematical theory of saving. Econ J 38:543-559

Tol RSJ (2010) International inequity aversion and the social cost of carbon. Clim Change Econ 1:21-32

Traeger CP (2013) Discounting under uncertainty: disentangling the Weitzman and the Gollier effect. J Environ Econ Manag 66:573-582

Weitzman ML (1998) Why the far-distant future should be discounted at its lowest possible rate. J Environ Econ Manag 36:201-208

Weitzman ML (2001) Gamma discounting. Am Econ Rev 91:260-271 
Weitzman ML (2007) Subjective expectations and asset-return puzzles. Am Econ Rev 97:1102-1130

Weitzman ML (2009) On modeling and interpreting the economics of catastrophic climate change. Rev Econ Stat 91:1-19

Weitzman ML (2010) Risk-adjusted gamma discounting. J Environ Econ Manag 60:1-13

Weitzman ML (2012) The Ramsey discounting formula for a hidden-state stochastic growth process. Environ Resour Econ 53:309-321

Weitzman ML (2013) Tail-hedge discounting and the social cost of carbon. J Econ Lit 51:873-882

Publisher's Note Springer Nature remains neutral with regard to jurisdictional claims in published maps and institutional affiliations. 